\title{
Does Unemployment Hurt Less if There is More of it Around? A Panel Analysis of Life Satisfaction in Germany and Switzerland
}

\author{
Daniel Oesch ${ }^{1, *}$ and Oliver Lipps ${ }^{2}$
}

\begin{abstract}
This article examines the existence of a habituation effect to unemployment: Does the subjective well-being of unemployed people decline less if unemployment is more widespread? The underlying idea is that unemployment hysteresis may operate through a sociological channel: if many people in the community lose their job and remain unemployed over an extended period, the psychological cost of being unemployed diminishes, and the pressure to accept a new job declines. We analyse this question with individual-level data from the German socio-economic panel (1984-2010) and the Swiss household panel (2000-2010). Our fixed-effects estimates show no evidence for a mitigating effect of high surrounding unemployment on the subjective well-being of the unemployed. Becoming unemployed hurts as much when regional unemployment is high as when it is low. Likewise, the strongly harmful impact of being unemployed on well-being neither wears off over time, nor do repeated episodes of unemployment make it any better. It thus appears doubtful that an unemployment shock becomes persistent because the unemployed becomes used to, and hence reasonably content with, being without a job.
\end{abstract}

\section{Introduction}

Since the 1980s, unemployment in western Europe tended to increase much faster during a recession than it receded during the ensuing cyclical upturns. This phenomenon of unemployment persistence has come to be known as 'hysteresis' (Blanchard and Summers, 1986). A possible explanation for hysteresis is that prolonged periods of substantial unemployment lead to a 'culture of unemployment'. As the number of unemployed people in a region increases and the average duration of unemployment extends, the stigma associated with living on welfare benefits diminishes, and the subjective well-being of the unemployed improves. Unemployment becomes a status people get used to and the social norm of working weakens (Blanchard, 1988: p. 26; Lindbeck et al., 1999: p. 3). Hysteresis may thus operate through a sociological channel: if an unemployment crisis hits many people in the community, the psychological cost of being unemployed diminishes, and the pressure for the unemployed to accept a new job declines.

Increasing unemployment may also have the opposite impact on unemployed workers' subjective well-being. As regional unemployment increases and unemployment spells become longer, jobless people face ever bleaker labour market prospects. Contexts of high and persistent unemployment may thus leave psychological scars on the unemployed and impair their readiness to engage in efficient job search behaviour. Hysteresis would then be the consequence of the adverse effect an unemployment crisis has on the jobless' well-being-and not the result of a moderating effect (Darity and Goldsmith, 1993: pp. 59-62).

Our article aims to examine these competing assumptions with panel data. By now, it is a well-established fact that becoming unemployed strongly depresses individuals' subjective well-being (e.g. Whelan, 1994; Winkelmann and Winkelmann, 1998; Clark, 2003). However, much more controversial is the question of whether unemployment hurts less if there is more of it around, and if it lasts

\footnotetext{
${ }^{1}$ Life Course and Inequality Research Centre (LINES), Institute of Social Sciences, University of Lausanne; ${ }^{2}$ FORS, Swiss Centre of Expertise in Social Sciences, University of Lausanne, CH-1015 Lausanne, Switzerland

${ }^{*}$ Corresponding author. Institute of Social Sciences, University of Lausanne, CH-1015 Lausanne, Switzerland. Email: daniel.oesch@unil.ch
} 
longer. We thus examine whether unemployment is less (or more) detrimental to subjective well-being (i) in periods of high than low unemployment, (ii) in long- than short-term unemployment, and (iii) in later than earlier spells of unemployment.

Our analysis is based on two countries with large differences in regional unemployment-Germany and Switzerland-and exploits two particularly well-suited data sets for the questions at hand, the German socio-economic panel (SOEP) (1984-2010) and the Swiss household panel (SHP) (2000-2010). Our study takes advantage of the data's longitudinal design and analyses how the entry into (and on-stay in) unemployment changes the reported life satisfaction of the unemployed over time in different contexts.

This question has clear policy implications. If the subjective well-being of the unemployed declines less in a context of higher surrounding unemployment and even increases during longer unemployment spells, a strategy against hysteresis needs to put greater strain on the unemployed to force them back onto the labour market. In contrast, if higher ambient unemployment and longer unemployment duration lead to more distress among the jobless, there is no point in retrenching benefits. A more adequate response would then consist in active labour market policies, which support the unemployed in their search process.

Our article is structured as follows. The next section reviews the literature on the link between the social context and subjective well-being of the unemployed. The section on 'Data and estimation method' discusses the advantages of panel data and presents our estimation method. The section on 'Descriptive results' provides descriptive evidence, and the section on 'Multivariate results' shows the estimation results of fixed-effects models. The 'Conclusion' section discusses the policy implications of our findings.

\section{Surrounding Unemployment and the Well-Being of the Unemployed}

What is the likely influence of ambient unemployment and unemployment duration on the life satisfaction of the jobless? The seminal contribution by Jahoda, Lazarsfeld, and Zeisel (1933/1971) suggested that an unemployment crisis is all the more devastating for a community, the more people it concerns, the longer it lasts. Likewise, from a purely utilitarian point of view, the loss of a job should be particularly hurtful in regions and periods with high rates of unemployment, where a job is a rare commodity and as such very valuable. Accordingly, individuals losing their job in high-unemployment regions face bleaker labour market perspectives than the unemployed in economically thriving regions and should thus be more strongly affected in their well-being.

Drawing a parallel to the literature on unemployment scarring (Gangl, 2006), it is possible that the shortage of job vacancies in high-unemployment regions constrains workers' search activity and thus inflicts a psychological scar effect on the unemployed. A similar reasoning may apply to long-term unemployment: as time goes by, social isolation grows and despair sets in. High aggregate unemployment and long individual unemployment may thus have a demoralizing effect on the jobless and their search behaviour. This should, in turn, lead to a less-efficient matching process and thereby fuel unemployment hysteresis (Darity and Goldsmith, 1993: p. 59).

The arguments based on bleak labour market prospects contrast with a much larger-and still growingliterature that emphasizes the existence of a work-based social norm. In the 1980s, Olivier Blanchard (1988: p. 26) argued that it is not so much economic pressure, but social stigma that motivates the unemployed to take on a new job. The underlying idea is that in times of near full employment, being unemployed reflects negatively on an individual. Yet, attitudes toward the unemployed change with higher levels of unemployment, when stigma and social disapproval become less widespread. An increase in the number of people who receive unemployment benefits thus weakens the social norm to earn one's own money. Likewise, long and frequent spells of unemployment possibly change the values, social relations, and lifestyle of the unemployed. They may come to appreciate their increase in leisure time and suffer less from a negative reputation effect (Lindbeck et al., 1999: p. 3; Frey and Stutzer, 2002: p. 421; Clark, 2003: p. 346). Unemployment thus becomes a way of life that results - if it lasts long enough and is geographically concentrated-in a 'culture of worklessness'. Accordingly, the social-norm hypothesis expects the jobless to suffer less from unemployment where surrounding unemployment is high and unemployment duration long. Through this micro-level mechanism, high levels of unemployment should perpetuate themselves and result in hysteresis.

In the happiness literature, the existence of a social norm effect is taken for granted. Being unemployed is expected to depress people's well-being less, if they are not alone in their fate (Frey and Stutzer, 2002: p. 421; Layard, 2005: p. 67). However, the empirical evidence for such an effect is surprisingly scarce and often contradictory. This applies in particular to surrounding unemployment. In a fixed-effect analysis of the British household panel survey 1991-1997, Clark (2003: p. 340) 
found higher regional unemployment to have no influence on unemployed women, but to possibly increase the well-being of unemployed prime-age men. In contrast, the same author comes to the opposite result for Germany. Using the German SOEP 1984-2006, he found that higher regional unemployment does not affect unemployed men, but significantly diminishes the well-being of unemployed women (Clark et al., 2010: p. 58). A cross-sectional analysis on 835 unemployed Germans from the SOEP 2001 even finds higher regional unemployment to be significantly correlated with lower life satisfaction of the unemployed (Grözinger and Matiaske, 2004: p. 99). The same conclusion emerges from a fixed-effects panel analysis of the SOEP 19992009: individual unemployment seems more hurtful when aggregate unemployment is higher (Chadi, 2011).

For several smaller countries, there is indirect evidence on the link between unemployment and well-being. A cross-sectional analysis for Switzerland finds the unemployed to have lower well-being in communities with a stronger work norm-that is in the mainly conservative rural communities where a majority of people voted in favour of unemployment benefit cuts (Stutzer and Lalive, 2004: p. 715). In contrast, a study based on Swedish panel data found no indication of an unemployment culture (Nordenmark, 1999: p. 56); neither did a parallel Danish study unearth any signs of a dependency culture, as even among those individuals out of employment for several years most preferred to work (Goul Andersen, 2002: p. 188). In Ireland, psychological distress has been found to increase more strongly among professionals and managers who had become unemployed than among manual workers (Whelan, 1994: p. 56) - a result confirmed by a British panel data analysis (Andersen, 2009: p. 17). Likewise, different studies have found more men than women to suffer more from unemployment (e.g. for Britain, Clark, 2003: p. 337). Two explanations are possible. The social norm to work may be stronger for the highly educated in general and men in particular than for the lesseducated and women. Alternatively, professionals and managers may enjoy their (more rewarding) work more than low-skilled workers-and men more than women. Accordingly, these categories may suffer more when losing their job.

The evidence is less ambiguous with respect to the well-being effect of unemployment duration. A Swedish cross-sectional study finds the long-term unemployed to have lower well-being than the short- and mid-term unemployed, all the while showing unchanged orientation toward work: 66 per cent of the long-term unemployed answered they would work after a major lottery win as compared with 63 per cent of the short- and mid-term unemployed (Åberg, 2001: p. 137). Panel data studies are better suited to uncover the effect of long-term unemployment on well-being. An Australian panel data study finds the well-being of unemployed individuals to decline with increasing unemployment length (Carroll, 2007: p. 296). In contrast, studies that use panel data from Britain and Germany report that well-being remains constant-constantly low-during people's unemployment (Winkelmann and Winkelmann, 1998; Clark, 2006; Clark et al., 2008).

In sum, the social-norm explanation of hysteresis maintains that weaker social pressure takes off some of the mental burden of unemployment-and thus renders it persistent. If the social-norm explanation is correct, we should observe the following three implications at the micro-level:

(i) Periods of higher regional unemployment weaken the social norm to work and thus lead to a smaller decline in the well-being of the unemployed (contextual habituation effect).

(ii) Longer individual unemployment induces the unemployed to adapt their lifestyle to unemployment and diminishes its negative effect on well-being (temporal habituation effect).

(iii) Frequent unemployment spells lead the unemployed to get used to be on welfare benefits and mitigate unemployment's negative effect on well-being (life-course habituation effect).

The hypothesis focussing on bleak labour market prospects expects the opposite outcome. If high unemployment rates provide negative information about people's job perspectives, they should lead to a larger drop in the well-being of the jobless. The three types of habituation effects outlined earlier should thus not be observable. Of course, there is a good chance that the two mechanismssocial norms and labour market prospects-cancel each other out. We differentiate the two effects by arguing that social norms are primarily determined by regional unemployment (neighbours' and friends' labour market situation), whereas labour market prospects should be more closely linked to sectoral unemployment (job perspectives in one's occupational field).

\section{Data and Estimation Method}

We analyse the impact unemployment has on subjective well-being for Germany, 1984-2010, and Switzerland, 2000-2010. There are two rationales for our country selection. First, regional labour markets differ strongly in these two countries. During the past two decades, no other western European country witnessed stronger variation in regional unemployment than Germany, with rates ranging 
from less than 3 per cent in Baden-Württemberg and Bavaria $(1990,1991,1992)$ to more than 20 per cent in Saxony-Anhalt and Mecklenburg-West Pomerania (1998, 2004, 2005). Regional disparities in unemployment are smaller in Switzerland, but its linguistic communities possibly differ in their work norms. Lower unemployment in German- than French-speaking Switzerland has been attributed to more positive attitudes toward work (Brügger et al., 2009). Thus, Switzerland is a particularly favourable test case for the social norm hypothesis of unemployed people's well-being. A second reason for our country selection is the availability of high-quality panel data: the first 27 waves of the German SOEP, 1984-2010, (see Wagner et al., 2007) ${ }^{1}$ and 11 waves of the Swiss household panel (SHP, 2000-2010, see Voorpostel et al., 2010). ${ }^{2}$

We restrict our sample to respondents aged between 20 and 65 years who were in paid employment at the date of the first measurement. We thus leave aside left-censored episodes of unemployment, but keep all those individuals in our sample who were at risk to experience the event under study: unemployment (Brüderl, 2010: p. 979). This provides us with a total of 271,186 person-years for Germany and 46,450 person-years for Switzerland. However, the phenomenon of interest-transitions from employment to unemployment-is much less frequent: there are 8,310 transitions in the German SOEP, but only 330 in the SHP. Accordingly, our analyses for Germany will be both more detailed and of greater substantive interest than those for Switzerland.

Our dependent variable is people's self-reported subjective well-being and is based on the question 'How satisfied are you at present with your life as a whole?', with answers ranging from 0 (totally dissatisfied) to 10 (totally satisfied). The variable's distribution is shown in the appendix (see Figure A1). Life satisfaction seems somewhat higher among Swiss than German respondents with an average of 7.96 as compared with 7.02 for Germany. But the majority of respondents in both Germany and Switzerland appear satisfied with their lives, the value of 8 being the modal category.

Our key independent variable is labour market status. We distinguish four states: (i) employment (other than a year before becoming unemployed), (ii) employment a year before becoming unemployed, (iii) the first year of unemployment, (iv) the second and following years of unemployment. ${ }^{3}$ We create a separate category for employment in the year preceding unemployment because people are likely to anticipate their unemployment. As dismissal decisions and firm closure generally imply a period of notice, subjective well-being may already decline before unemployment actually sets in. By further distinguishing the first from the following years of unemployment, we examine whether unemployment becomes better or worse with duration.

We construct an additional variable for the unemployment spell to identify the first observed episode of unemployment from the ensuing ones. The objective is to find out how the repeated experience of unemployment affects people's well-being. Even though our panel data only cover one (Switzerland) or three (Germany) decades, we can determine the number of unemployment spells over respondents' entire life course, thanks to the biography data included in the SOEP and SHP. ${ }^{4}$ In Germany, 60 per cent of respondents who have ever been unemployed accumulated at least three episodes over their observed biography. In the Swiss sample, biographic information is only available for two-thirds of the respondents, and the number of repeated unemployment spells lies much lower.

Further key variables are the aggregate unemployment rates on the regional and sectoral level. For Germany, yearly unemployment rates are distinguished for the Bundesländer ${ }^{5}$ and range from 2.3 (Baden-Württemberg, 1991) to 22.4 per cent (Sachsen-Anhalt, 2004). For Switzerland, regional unemployment rates are calculated for six main regions and vary between 1.5 (Central Switzerland, 2002) and 6.7 per cent (Lake Geneva Region, 2005). At the sectoral level, unemployment rates range from 2.3 (manufacturing, 1984) to 17.6 per cent (construction, 2005) in Germany and from 1.3 (construction, 2001) to 5.2 per cent (sales, tourism, and personal services, 2005) in Switzerland.

We add controls for age, age squared, decade, living together with a partner and three educational levels. Moreover, we control for post-government household income (in its logarithmic form). The idea is that the well-being of the jobless may simply decrease with prolonging unemployment because the jobless are no longer entitled to benefits-and thus suffer from the drop in their household's financial resources rather than from being unemployed. Fixed effects models do not account for this time-variant source of unobserved heterogeneity.

Because several studies indicate that the effect of surrounding unemployment on well-being differs by sex, we estimate separate models for men and women. Furthermore, to account for regional differences, we use dummy variables for the Bundesländer in Germany and the main regions in Switzerland (Italian-speaking Ticino is dropped from the analysis). ${ }^{6}$ Descriptive statistics for all these variables are shown in the appendix (see Table A1).

The analysis of subjective well-being typically faces two problems. First, the direction of causality is unclear, as unemployment is likely to depress people, but depressed people also make less productive workers and are thus 
prone to become unemployed. Second, unobserved common determinants of well-being and unemployment such as personality traits may lead to spurious correlations: unhappy people are both more likely to lose their job and to report low levels of life satisfaction. Although these two problems are acute with cross-sectional data, longitudinal data offer a way out. By providing repeated observations for the same individual over time, panels make it possible to address the issue of causality and to control for unobserved individual characteristics that are time invariant, but correlated with unemployment (Winkelmann and Winkelmann, 1998: p. 2).

This leads us to our estimation method. To get rid of time-invariant unobserved heterogeneity, we need to work with a fixed-effects model that only exploits within-person variance. However, fixed-effects models cannot estimate the effect of time-constant variables such as education. This is a problem for our analysis because unemployment may affect the well-being of the high- and low-educated differently. For this reason, we resort to a mixed-effects model that combines the results from fixed-effects estimators for time-variant variables with random-effects estimators for time-invariant variables (see Halaby, 2004: p. 530; Brüderl, 2010: 976). Technically, this implies that we estimate a random-effects model in which all the timevariant covariates are demeaned, thus providing us the fixed-effects estimators, whereas a few time-invariant covariates such as education are left unchanged and thus correspond to the random-effects estimates. Moreover, we

Germany, 1984-2010

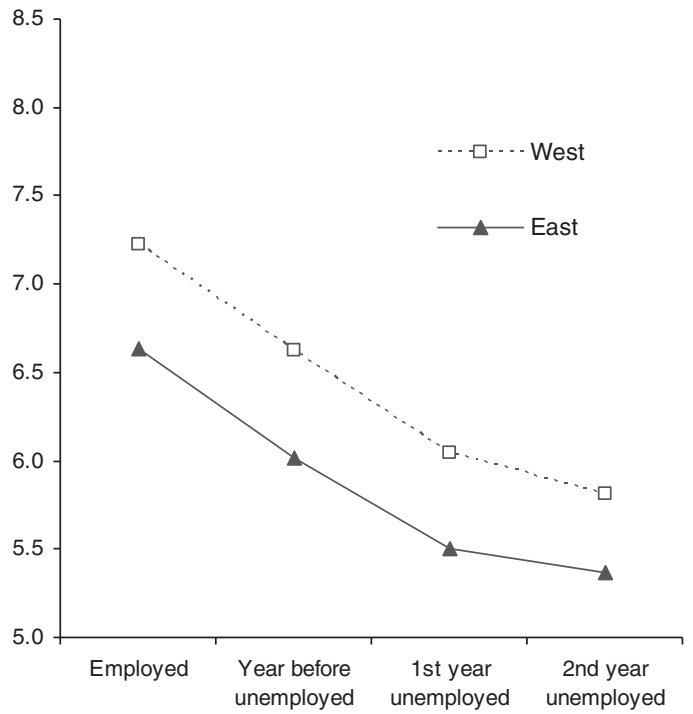

treat our ordinal well-being scale as if it were a cardinal variable, which allows us to estimate linear models. Several studies show that whether ones assumes cardinality or ordinality of the satisfaction answers in the SOEP leads to identical substantive findings (e.g. Ferrer-i-Carbonell and Frijters, 2004: p. 655; Clark et al., 2008: p. 236). Finally, we correct for auto-correlation in our panel data by using panel-corrected 'robust' standard errors.

\section{Descriptive Results}

We start our analysis with descriptive statistics and show the well-being score of the following four categories in Figure 1: (i) all the employed (other than those becoming unemployed in the subsequent year), (ii) the employed in the year before becoming unemployed, (iii) the unemployed in their first year of unemployment, and (iv) the unemployed in the second and following years of unemployment. Simply using our data as pooled cross-sections, these average scores in well-being are further differentiated geographically-for West and East Germany and for German- and French-speaking Switzerland. Three results are noteworthy.

First, not only unemployment, but already the anticipation of job loss depresses life satisfaction. Hence, individuals still employed but about to become unemployed over the following year report substantially lower well-being than those in stable employment. This is not surprising, as plant closure and individual lay-offs

Switzerland, 2000-2010

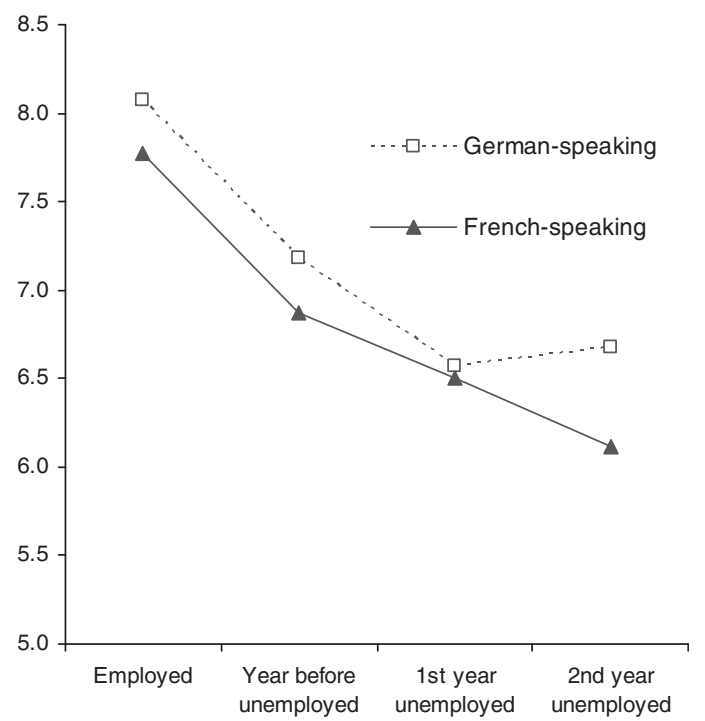

Figure 1 Subjective well-being (measured on a scale from 0 to 10) and employment status-results from a pooled cross-sectional analysis. 


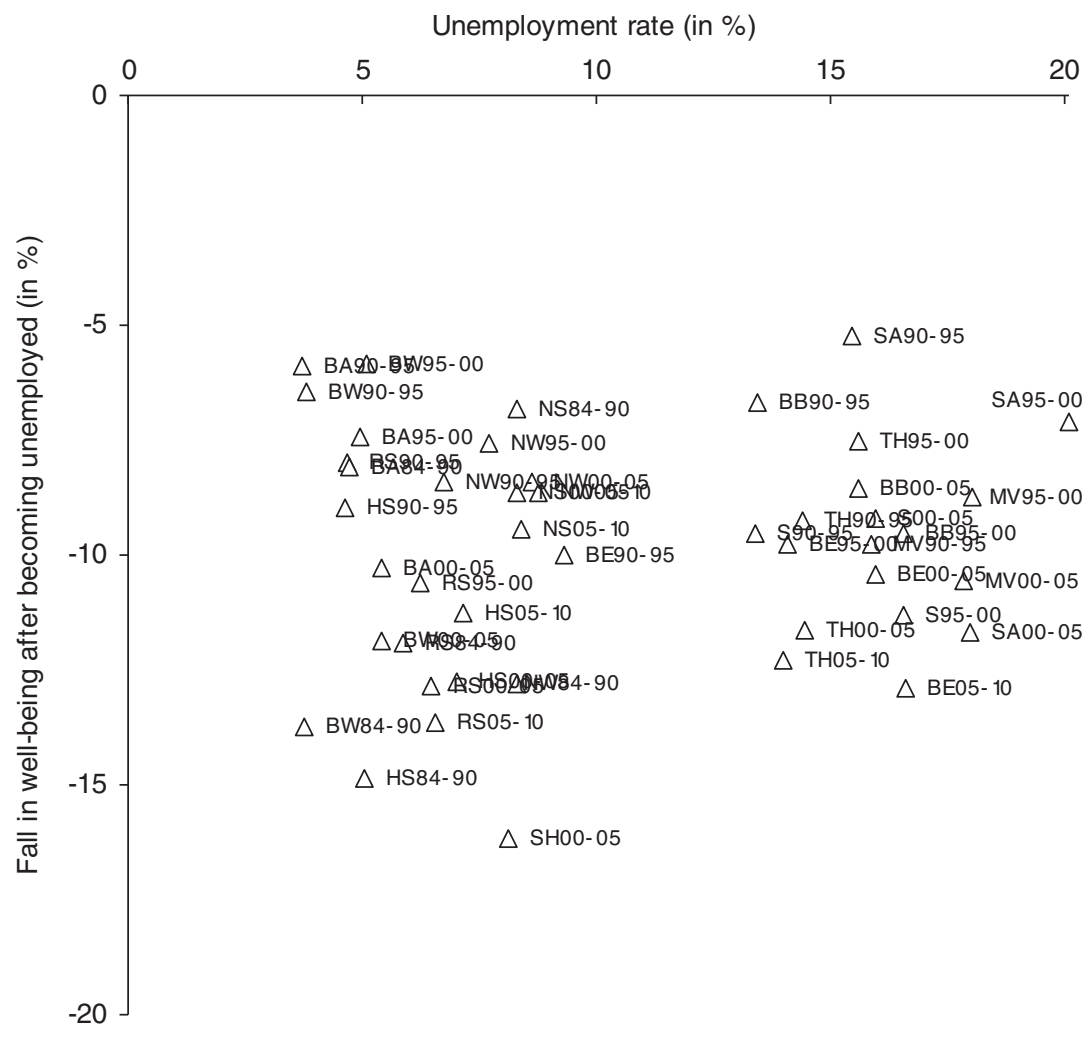

Figure 2 Regional unemployment and the fall in individuals' well-being when becoming unemployed, averaged over five 5-year periods in German regions.

Notes: Observations for the German Bundes/änder are averaged over the following periods: 1984-1990 (only former West Germany), 1990-1995, 1995-2000, 2000-2005, 2005-2010.

Key: B = Berlin, BA = Bavaria, BB = Brandenburg, BW = Baden-Württemberg, $\mathrm{H}=$ Hessen, NS = Lower Saxony, MV = MecklenburgWest Pomerania, NW = North Rhine-Westphalia, RS=Rhineland-Palatinate/Saarland, $S=$ Saxony, SA=Saxony-Anhalt, SH= Schleswig-Holstein and $\mathrm{T}=$ Thuringia.

are usually announced several months ahead. More surprisingly, Figure 1 shows the long-term unemployed to have lower levels of well-being than the short-term unemployed. Except in German-speaking Switzerland, the long-term unemployed are everywhere the unhappiest labour market category.

Second, there is a striking similarity in Germany and Switzerland's well-being results. Although the general level of life satisfaction is somewhat higher in Switzerland than in Germany, the well-being gap between people in stable employment and people in their first year of unemployment is almost identical: in the first year of unemployment, subjective well-being drops by 16 per cent in West Germany and French-speaking Switzerland, by 17 per cent in East Germany and by 19 per cent in German-speaking Switzerland.

Third, regional levels of well-being differ only moderately in Switzerland, but substantially in Germany. The respondents in East Germany are significantly unhappier than those in the West in every single labour market state. Contrary to what the social norm argument expects, this finding does not only apply to the employed but also the unemployed. Hence, despite substantially higher ambient unemployment, unemployed East Germans report lower well-being than the unemployed in West Germany. The same observation can be made for Switzerland. Although unemployment is more widespread in French-speaking Switzerland, the well-being of the jobless is lower than in German-speaking Switzerland.

These results are based on pooled cross-sections and do not take advantage of our data's panel structure. They thus need to be interpreted with caution. Cross-sectional analyses regularly find the long-term unemployed to have lower well-being than the short-term unemployed-yet, the result may be driven by a selection process. Happier people make better job candidates and find a job more 


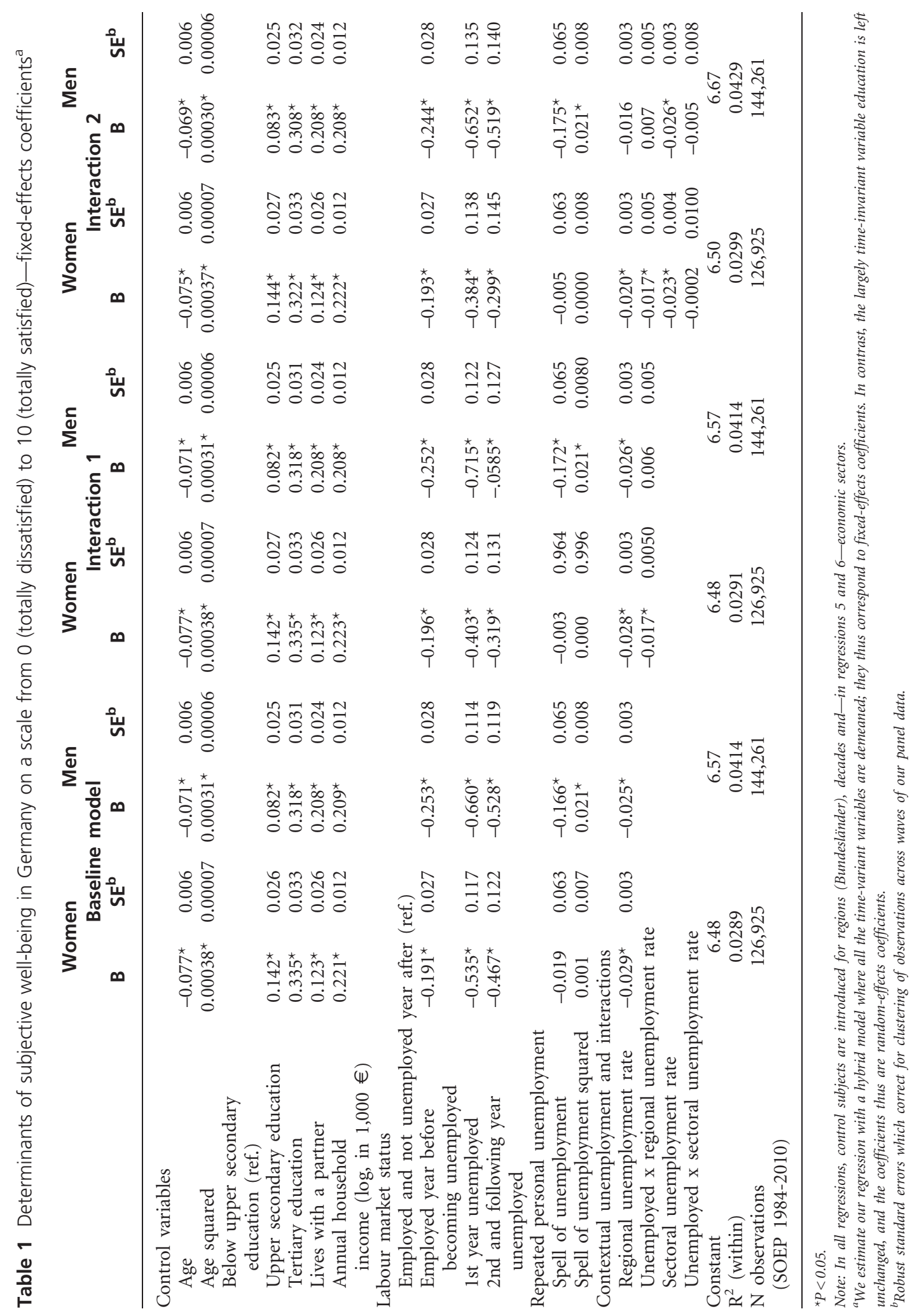




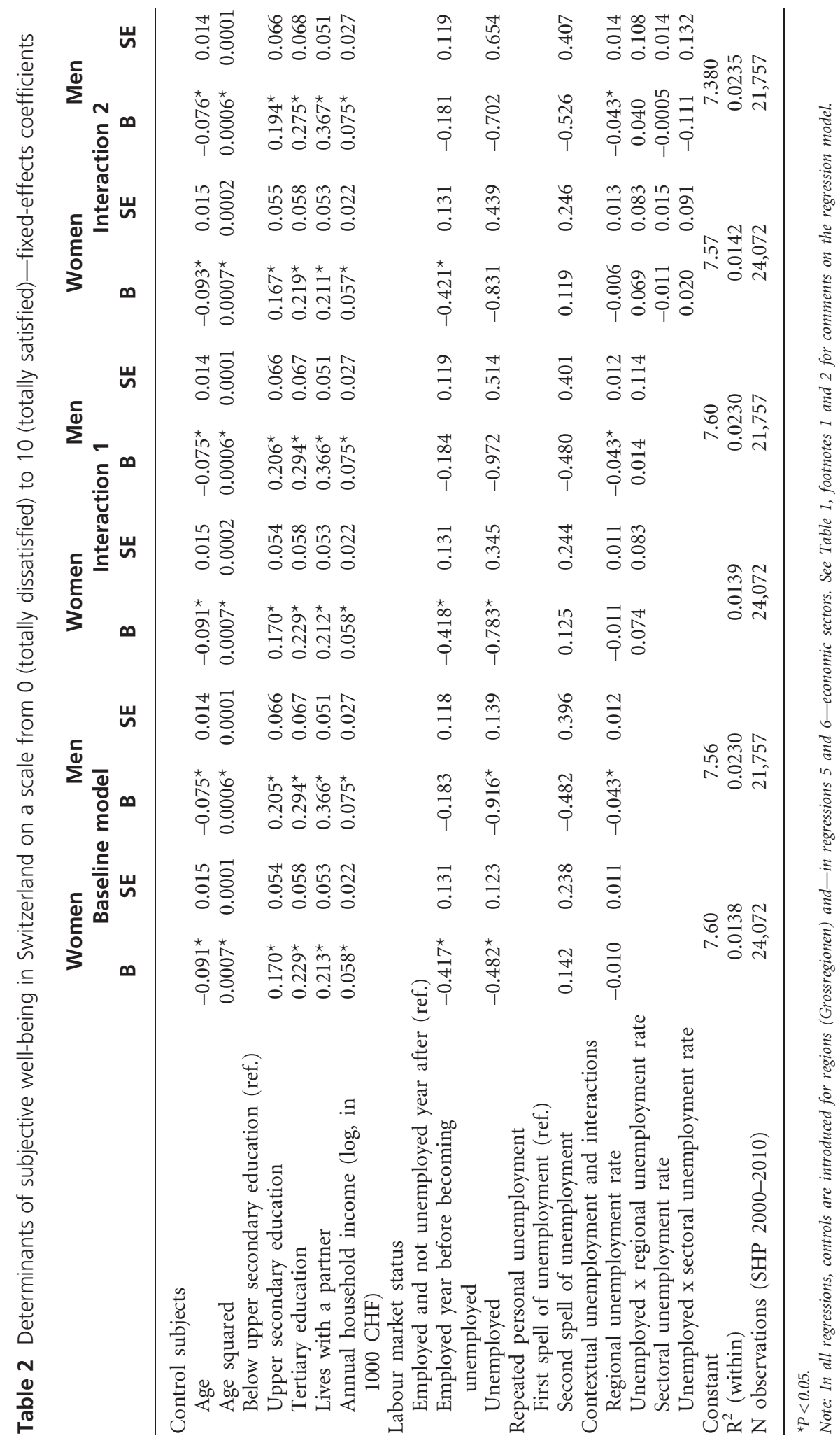


quickly than unhappy people. To obtain more reliable evidence on the effect of unemployment on well-being, we need to control for unobserved character traits and hence different baseline levels of life satisfaction (individuals' unobserved heterogeneity) by following the same individual over time.

Accordingly, we compute the change in people's self-reported well-being when transiting from employment (in year $t_{1}$ ) to unemployment (in year $t_{2}$ ). The fall in respondents' well-being when becoming unemployedaveraged over the German regions (Bundesländer) for five 5 -year periods-is then plotted in Figure 2 against the regional unemployment rates. The changes in well-being are only shown for a region if they are statistically significant; typically, they need to be based on a minimum of 70 to 80 individual transitions into unemployment (a requirement not met by the regions of our smaller Swiss sample). This leaves us with observations for 46 region-periods in Germany. The results reveal a remarkable absence of correlation between the regional unemployment rate and the average drop in the unemployed people's well-being. Although East German regions have much higher levels of surrounding unemployment (and thus cluster to the right in Figure 2), the average fall in well-being is not significantly different from that in the West German regions. To give an example, average unemployment for the period 2000-2005 was less than 6 per cent in Bavaria, but more than 16 per cent in Saxony and Mecklenburg-West Pomerania. Nonetheless, the average drop in well-being associated with a transition from employment (in the year before becoming unemployed) to unemployment (in the first year of unemployment) amounted to 10 per cent in all three regions (Bundesländer). The unemployed in Germany do not seem to take job loss more lightly in regions and periods with higher ambient unemployment.

\section{Multivariate Results}

Figures 1 and 2 throw serious doubt on the hypothesis that unemployment hurts less the more widespread it is, and the longer it lasts. However, these descriptive results are tentative and need to be substantiated by multivariate analysis. For this reason, we estimate the impact of labour market status, unemployment spells, and control variables on subjective well-being for men and women.

The results for Germany and Switzerland are shown in Tables 1 and 2. The baseline model indicates that individual unemployment has a strongly negative effect on well-being in both countries-even if we account for time-invariant personality traits (through fixed-effects) and time-variant covariates such as household income or changes in partnership (through control variables). To give an idea of the effect's size, unemployment's detrimental impact on life satisfaction clearly outweighs the beneficial influence of living together with a partner, being at least twice as important in Germany and Switzerland for men and women. In both countries, men seem to suffer more from being unemployed than women.

For both sexes and countries, we find a substantial anticipation effect of unemployment. Well-being decreases already in the year before actual unemployment sets in. In contrast, we find at best a weak habituation effect of unemployment. When household income is held constant between the first and second year of unemployment (a somewhat unrealistic assumption), the decline in well-being is slightly smaller in the second than the first year. However, the difference is only significant for German men. Unlike for other negative life events such as divorce or widowhood, people do not seem to get adapted to being unemployed. Our evidence supports the finding by Clark et al. (2008: p. 225) that 'unemployment starts off bad and stays bad'.

Our data do not show a habituation effect to repeated unemployment either. In Germany, men's well-being even appears to decline more when unemployment is experienced for the second or third time (even though the quadratic term suggests that this effect levels off and becomes positive for the small group of people experiencing more frequent unemployment episodes). Our reading of the results is that whether spells of unemployment are recurrent does not make a difference for well-being. Contrary to the thesis of an 'unemployment culture', having experienced job loss before and thus being used to unemployment does not seem to take off the mental burden of a new unemployment episode.

How does surrounding unemployment affect life satisfaction? In both countries, higher regional unemployment rates lead to a significant decrease in people's well-being. This result holds true even though we introduce dummy variables for Bundesländer in Germany and major regions in Switzerland, thus controlling for East German Länder and French-speaking regions where overall well-being is lower and aggregate unemployment higher.

High surrounding unemployment makes the workforce in general more miserable, but what about the jobless? In a second model, we introduce interaction effects between regional and individual unemployment to examine this question more specifically. Neither for Germany nor Switzerland do we find the mitigating social-norm effect of higher regional unemployment on personal unemployment that the happiness literature takes for given (Frey and Stutzer, 2002: p. 421; Layard, 2005: p. 67). For Switzerland, there is no effect whatsoever. Although the interaction effect for unemployed men in Germany is positive (which 
would suggest that higher unemployment rates make life easier for the jobless), the coefficient is not significant. In contrast, the interaction effect is significant and negative for unemployed women in Germany and indicates that jobless women suffer more from high surrounding unemployment than do employed women. The finding that high surrounding unemployment affects women more negatively than men has been made before for Britain (Clark, 2003) and Germany (Clark et al., 2010).

The social-norm effect may well exist-but be cancelled out by the negative information that high unemployment rates provide for unemployed workers' labour market prospects. We examine this hypothesis in a third model (see Tables 1 and 2) by introducing sectoral unemployment rates and an interaction term between sectoral and individual unemployment. The rationale is that re-employment prospects should be more closely linked to the economic situation in one's sector than in one's region-contrary to social norms, which are expected to operate through geographical proximity. Our results show that sectoral unemployment strongly depresses the well-being of both employed workers and jobless people in Germany-but without changing anything else. Even if we control for sectoral unemployment rates and its interaction with people's own unemployment, higher regional unemployment rates do not show a mitigating effect on the well-being of the jobless. Sectoral unemployment rates have a substantially larger impact on subjective well-being than do regional unemployment rates in Germany-but not in Switzerland, where they do not seem to be significant.

\section{Conclusion}

This article opened with the question of whether there is a habituation effect to unemployment. We examined this issue against the backdrop of a popular view among both economists and laymen that an unemployment shock becomes persistent because the ever more numerous unemployed become used to-and hence reasonably content with-being without a job. As unemployment becomes more widespread, the social norm to work weakens and the unemployed are no longer ostracized and accordingly suffer less from being without a job. Our analysis provides no support for this argument. Four results are noteworthy.

First, higher levels of regional unemployment do not moderate the psychological cost of individual unemployment. Unemployed people in economically barren East German regions experience a similar drop in well-being when losing their job as the unemployed in more prosperous regions of southern Germany. The same finding applies to Switzerland. No matter the regional unemployment rate, job loss massively impairs subjective well-being.

Second, gender makes a difference. Although unemployed men in Germany do not suffer more from high ambient unemployment rates than employed men, this is the case for unemployed women. But for men and women alike, the unemployed are less satisfied with their lives in regions and periods with high unemployment rates than in regions and periods with low unemployment rates.

Third, unemployment does not become much better with duration. The unemployed appear almost as unhappy in their second and following year(s) of unemployment as in the first year. Unlike what the argument of a 'culture of worklessness' maintains, the bulk of the long-term unemployed do not seem to install themselves comfortably in a life without a job.

Fourth, we do not find a life-course habituation effect to unemployment. Recurrent spells of unemployment do not mitigate the strongly detrimental impact of job loss on subjective well-being. Whether unemployment has been experienced before does not change the fall in people's well-being when becoming unemployed.

There are several limits of our analysis. To begin with, the use of smaller regions than the Bundesländer or Swiss major regions would be preferable. Social norms to work may differ locally rather than regionally. Smaller regional units would be useful to differentiate local labour markets and identify pockets of high unemployment from those of full employment. For the moment, the number of observations-individual transitions into unemployment-is too low to warrant such a strategy. However, with each new wave of the German SOEP, such an approach becomes more realistic. As for Switzerland, the Swiss household panel still records only a small number of transitions into unemployment. Accordingly, results are more robust for Germany.

Moreover, as forthcoming waves of panel data increase the number of observations, it may become feasible to use an external source of unemployment such as losing one's job after firm closure. By using this instrument for unemployment, we would avoid the potential bias of time-variant unobserved variables (linked for instance to health or family problems) causing both unemployment and decreasing well-being. In the absence of such an exogenous instrument, our analysis possibly overestimates the impact of becoming unemployed on people's life satisfaction.

These limitations notwithstanding, our main finding holds. Regardless of whether unemployment rates are high or low in a community, becoming unemployed strongly decreases people's well-being. The unemployed find it difficult to come to grips with being without a 
job, even if they have time to adapt to the new situation, and if spells of unemployment are recurrent. These results throw serious doubt on the argument that hysteresis is due to the fact that widespread unemployment reduces the psychological costs of being jobless and thus makes unemployment, to a greater extent, voluntary.

In policy terms, our results imply that a strategy primarily trying to lower aggregate unemployment by reducing unemployed workers' well-being is bound for little success-the subjective well-being of the unemployed is already very low. Putting greater strain on them by cutting unemployment benefits and shortening entitlement periods appears to just make difficult lives more miserable. A more promising strategy may consist in the combination of (a) efficient job-placement and training programmes that help people to move from welfare to work with (b) fiscal and monetary policies that fully exploit an economy's growth potential and create the job vacancies for the unemployed to effectively find work (Oesch, 2010). Based on evidence of people's subjective well-being, these policies seem more rational components of a full-employment strategy than efforts aimed at further pressurizing the unemployed.

\section{Notes}

1 Note that German data before 1990 refer to West Germany only.

2 The question about life satisfaction was not yet asked in the first wave of the SHP in 1999.

3 Unemployment refers to registered unemployment in Germany and to self-reported unemployment in Switzerland.

4 We are grateful to one of the reviewers to have drawn our attention to the biography data.

5 Because of its small size, the Bundesland of Saarland is combined with Rhineland-Palatinate.

6 There are too few observations of unemployed individuals for Italian-speaking Ticino, the smallest of Switzerland's main regions.

\section{Acknowledgements}

We are grateful to Alexandra Stam and Heinz-Herbert Noll for their help with the data and to Jean-Marc Falter, Michael Gebel, Rafael Lalive, and the two anonymous reviewers for their useful comments. This article has been written within the National Center of Competence in Research 'LIVES-overcoming vulnerability: life course perspectives', financed by the Swiss National Science Foundation.

\section{References}

Åberg, R. (2001). Equilibrium unemployment, search behaviour and unemployment persistency. Cambridge Journal of Economics, 25, 131-147.

Andersen, S. H. (2009). Unemployment and subjective well-being: a question of class? Work and Occupations, 36, 3-25.

Blanchard, O. (1988). Unemployment: getting the question right-and some answers. NBER Working Paper Series 2698.

Blanchard, O. and Summers, L. (1986). Hysteresis and the European unemployment problem. NBER Macroeconomics Annual, 1, 15-78.

Brüderl, J. (2010). Kausalanalyse mit Paneldaten. In Wolf, C. and Best, H. (Eds.), Handbuch der sozialwissenschaftlichen Datenanalyse. Wiesbaden: VS Verlag, pp. 963-994.

Brügger, B., Lalive, R. and Zweimüller, J. (2009). Does culture affect unemployment? Evidence from the Röstigraben. Cesifo Working Paper 2714.

Carroll, N. (2007). Unemployment and psychological well-being. Economic Record, 83, 287-302.

Chadi, A. (2011). Regional unemployment and norminduced effects on life satisfaction. SOEP Papers on Multi-Disciplinary Panel Data Research 387, DIW Berlin.

Clark, A. (2003). Unemployment as a social norm: psychological evidence from panel data. Journal of Labor Economics, 21, 323-351.

Clark, A. (2006). Unhappiness and unemployment duration. Applied Economics Quarterly, 52, 291-308.

Clark, A. et al. (2008). Lags and leads in life satisfaction: A test of the baseline hypothesis. Economic Journal, 118, F222-F243.

Clark, A., Knabe, A. and Rätzel, S. (2010). Boon or bane? Well-being, others' unemployment, and labor-market risk. Labour Economics, 17, 52-61.

Darity, W. and Goldsmith, A. (1993). Unemployment, social psychology, and unemployment hysteresis. Journal of Post-Keynesian Economics, 16, 55-71.

Ferrer-i-Carbonell, A. and Frijters, P. (2004). How important is methodology for the estimates of the determinants of happiness? Economic Journal, 114, 641-659.

Frey, B. and Stutzer, A. (2002). What can economists learn from happiness research? Journal of Economic Literature, 40, 402-435.

Gangl, M. (2006). Scar effects of unemployment: an assessment of institutional complementarities. American Sociological Review, 71, 986-1013. 
Goul Andersen, J. (2002). Coping with long-term unemployment: economic security, labour market integration and well-being. Results from a Danish Panel study, 1994-1999. International Journal of Social Welfare, 11, 178-190.

Grözinger, G. and Matiaske, W. (2004). Regional unemployment and individual satisfaction. In Grözinger, G. and van Aaken, A. (Eds.), Inequality: New Analytical Approaches. Marburg: Metropolis, pp. 87-104.

Halaby, C. (2004). Panel models in sociological research: theory into PRACTICE. Annual Review of Sociology, 30, 507-544.

Jahoda, M., Lazarsfeld, P. and Zeisel, H. (1971). Marienthal: The Sociography of an Unemployed Community. London: Tavistock. [translation; original: 1933] pp. xv-128.

Layard, R. (2005). Happiness: Lessons from a New Science. London: Penguin, pp. ix-310.

Lindbeck, A., Nyberg, S. and Weibull, J. (1999). Social norms and economic incentives in the welfare state. Quarterly Journal of Economics, 114, 1-35.
Nordenmark, M. (1999). The concentration of unemployment within families and social networks. European Sociological Review, 15, 49-59.

Oesch, D. (2010). What explains high unemployment among low-skilled workers? Evidence from 21 OECD countries. European Journal of Industrial Relations, 16, 39-55.

Stutzer, A. and Lalive, R. (2004). The role of social work norms in job searching and subjective well-being. Journal of the European Economic Association, 2, 696-719.

Voorpostel, M. et al. (2010). Swiss Household Panel User Guide 1999-2009, Wave 11. Lausanne: FORS.

Wagner, G., Frick, J. and Schupp, J. (2007). The German socio-economic panel study (SOEP) — scope, evolution and enhancements. Schmollers Jahrbuch, 127, 139-169.

Whelan, C. (1994). Social class, unemployment, and psychological distress. European Sociological Review, 10, 49-61.

Winkelmann, L. and Winkelmann, R. (1998). Why are the unemployed so unhappy? Evidence from panel data. Economica, 65, 1-15. 


\section{Appendix}

Germany 1984-2010 (N=271,186)

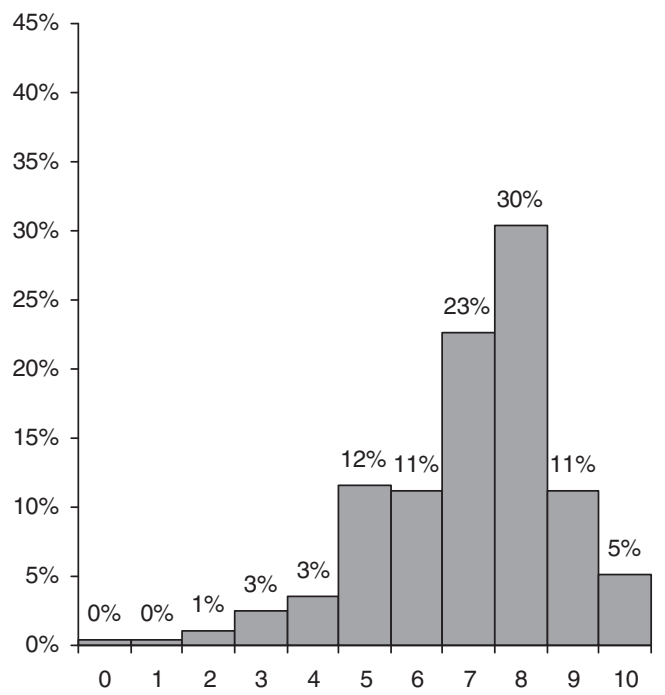

Switzerland 2000-2010 (N=46,450)

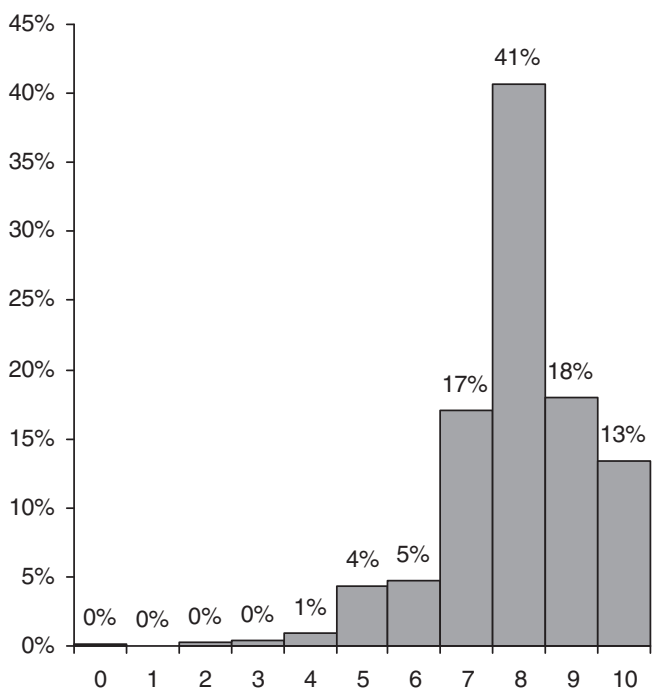

Figure A1 Distribution of responses to the question: 'How satisfied are you at present with your life as a whole?', answers ranging from 0 (totally dissatisfied) to 10 (totally satisfied)

Table A1 Descriptive statistics of the variables used in the analysis

Germany (SOEP)

\begin{tabular}{|c|c|c|c|c|c|c|}
\hline Variable & Mean & Min & Max & Mean & Min & Max \\
\hline Satisfaction with life & 7.02 & 0 & 10 & 7.96 & 0 & 10 \\
\hline Male & 0.53 & 0 & 1 & 0.47 & 0 & 1 \\
\hline Year & 1998.3 & 1984 & 2010 & 2005.1 & 2000 & 2010 \\
\hline Living with partner in household & 0.67 & 0 & 1 & 0.74 & 0 & 1 \\
\hline Age (in years) & 41.6 & 20 & 65 & 43.4 & 20 & 65 \\
\hline East (SOEP), French-speaking (SHP) & 0.19 & 0 & 1 & 0.28 & 0 & 1 \\
\hline $\begin{array}{l}\text { Post-government household income, } \\
\text { logarithm (in } 1000 € / \text { in } 1000 \mathrm{CHF} \text { ) }\end{array}$ & 3.35 & 0 & 8.36 & 4.46 & 0 & 7.68 \\
\hline 1st year unemployed & 0.031 & 0 & 1 & 0.007 & 0 & 1 \\
\hline 2nd and following year unemployed & 0.028 & 0 & 1 & 0.004 & 0 & 1 \\
\hline Education: less than upper secondary & 0.19 & 0 & 1 & 0.11 & 0 & 1 \\
\hline Education: upper secondary & 0.61 & 0 & 1 & 0.53 & 0 & 1 \\
\hline Education: tertiary & 0.20 & 0 & 1 & 0.36 & 0 & 1 \\
\hline Spell of unemployment & 3.26 & 1 & 11 & 1.18 & 1 & 2 \\
\hline Regional unemployment rate (\%) & 8.62 & 2.3 & 22.4 & 3.60 & 1.5 & 6.7 \\
\hline Sectoral unemployment rate (\%) & 6.87 & 2.3 & 17.6 & 2.85 & 1.3 & 5.2 \\
\hline
\end{tabular}

SOEP: $N=271,186$ (person-year observations); 29,979 individuals; 8,310 transitions from employment into unemployment. SHP: $N=46,450$ (person-year observations); 8,774 individuals; 330 transitions from employment into unemployment.

Switzerland (SHP) 